\title{
THE GLOBAL TANDEM-X DEM: PRODUCTION STATUS AND FIRST VALIDATION RESULTS
}

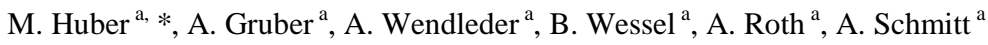 \\ a DLR, German Aerospace Center, 82234 Wessling Oberpfaffenhofen, Germany - (martin.huber, astrid.gruber, \\ anna.wendleder, birgit.wessel, achim.roth, andreas.schmitt)@dlr.de
}

KEY WORDS: TanDEM-X, DEM, InSAR, Global, Calibration, Mosaic, Block Adjustment, Validation

\begin{abstract}
:
The TanDEM-X mission will derive a global digital elevation model (DEM) with satellite SAR interferometry. Two radar satellites (TerraSAR-X and TanDEM-X) will map the Earth in a resolution and accuracy with an absolute height error of $10 \mathrm{~m}$ and a relative height error of $2 \mathrm{~m}$ for $90 \%$ of the data. In order to fulfill the height requirements in general two global coverages are acquired and processed. Besides the final TanDEM-X DEM, an intermediate DEM with reduced accuracy is produced after the first coverage is completed. The last step in the whole workflow for generating the TanDEM-X DEM is the calibration of remaining systematic height errors and the merge of single acquisitions to $1^{\circ} \mathrm{x} 1^{\circ} \mathrm{DEM}$ tiles. In this paper the current status of generating the intermediate DEM and first validation results based on GPS tracks, laser scanning DEMs, SRTM data and ICESat points are shown for different test sites.
\end{abstract}

\section{INTRODUCTION}

The final product of the TanDEM-X mission (Krieger et al. 2007) will be a global digital elevation model (DEM) with an absolute height error of $10 \mathrm{~m}$ and a relative height error of $2 \mathrm{~m}$ for $90 \%$ of the data, respectively. For this purpose at least two global coverages will be acquired with SAR interferometry. Areas with undulated terrain will be also observed from ascending and descending orbits, where necessary.

As a pre-version, the intermediate DEM (IDEM) will be produced for selected areas utilizing the first global coverage only. Even though the IDEM will not have the final TanDEM-X DEM accuracy, it provides a first impression on the prospective quality of this product.

In Chapter 2 the Mosaicking and Calibration Processor which stands at the end of the whole workflow for generating the TanDEM-X DEM is outlined. Then in Chapter 3 the current production status and validation results for different test sites and different reference data are shown. Additional product layers like height error map, amplitude image, water indication mask, coverage map, layover and shadow mask, interpolation mask and void mask are presented in Chapter 4.

\section{MOSAICKING AND CALIBRATION PROCESSOR}

Smaller systematic errors in the order of a few meters still remain in single acquisitions, although intensive instrument calibration and high precision orbit and baseline determination are conducted (Hueso et al. 2011).

Based on these acquisitions, which can be hundreds of kilometers long, the Integrated TanDEM-X Processor (ITP) generates single interferometric DEMs (Fritz et al. 2008). This so-called RawDEMs, having a size of typically $30 \mathrm{~km}$ by $50 \mathrm{~km}$, serve as input for the Mosaicking and Calibration Processor (MCP). The MCP consists of three components which are working independently from each other.

\subsection{MCP Preparation}

The first MCP component, the DEM Preparation processor, is a data-driven process. A first analysis of the RawDEM is performed which comprises a height discrepancy detection to a reference DEM (e.g. SRTM), a water body detection (Wendleder et al. 2012) and the extraction of calibration points (Huber et al. 2009, Huber et al. 2010) as input for the DEM calibration processor. After interactive quality control the result is stored for later processing.

\subsection{MCP Calibration}

The second component, the DEM Calibration Processor, is initiated by an operator. A processing request for a dedicated region is generated and sent to MCP. During the DEM Calibration a block adjustment procedure calculates offsets and tilts for each DEM acquisition (Gruber et al. 2009, Wessel et al. 2009). Therein, the elevation of tie-points in overlapping regions and ICESat points collected during MCP preparation are used to assure the relative and absolute height accuracy requirement. After quality control the correction parameters are stored within the annotation information for each RawDEM.

\subsection{MCP Mosaicking}

The third processor, the DEM Mosaicking Processor, is also initiated by an operator. A request for a defined region is generated and sent to MCP. Then, the DEM layers and additional information layers of all RawDEMs are mosaicked. After final quality control the mosaicked DEM is divided into DEM product tiles and archived.

\footnotetext{
* Corresponding author.
} 


\section{ASSESMENT OF THE INTERMEDIATE DEM}

\subsection{Production Status}

The acquisition of the first global coverage was completed by January 2012. The following two months were used for additional acquisitions of difficult areas. By April 2012 a total of 135,000 RawDEMs have been prepared for calibration and mosaicking. The remaining first year acquisitions are scheduled to be processed by ITP and MCP Preparation until May 2012. On basis of the available data first calibration and mosaicking tests are currently conducted. The operational IDEM production is planned to start in summer 2012.

By the end of March 2012 the acquisition of the second coverage started. It will take approximately one year followed by additional acquisitions where necessary. The final TanDEM-X product generation will start in 2013 and will be finished in 2014.

\subsection{Validation results}

Within the mosaicking the acquisitions are corrected by the estimated offset and tilts. The absolute accuracy of the resulting IDEM is checked against reference data like SRTM C-Band, ICESat data, high resolution DEMs or GPS tracks. Note that the differences are always calculated TanDEM-X - Reference data. In order to evaluate the relative height accuracy the absolute differences between neighboring acquisitions are computed. The requirement for the relative accuracy refers only to random errors (systematic errors are not considered). This means, that $90 \%$ of all differences around the mean have to be below $2 \mathrm{~m}$ in an area of $100 \mathrm{~km} \mathrm{x} 100 \mathrm{~km}$ (linear $90 \%$ point-to-point error).

3.2.1 Test Site Manitoba, Canada: The first test site consists of 8 acquisitions covering the north-western part of Minnesota, USA and the southern part of Manitoba, Canada. Figure 1 depicts the RawDEM outlines (red) and the resulting $1^{\circ} \times 1^{\circ}$ DEM tiles (black). The terrain of the test site is moderately flat and sparely vegetated. The calculated offsets and tilts are below $2 \mathrm{~m}$ and $8 \mathrm{~mm} / \mathrm{km}$ respectively.

The Tile N49W98 - the name refers to the lower left corner was investigated in more detail, as it contains a GPS track with a height accuracy of $<0.5 \mathrm{~m}$. The mean difference between TanDEM-X and the GPS heights is $-0.56 \mathrm{~m}$ with a standard deviation of $1.14 \mathrm{~m}$ (Figure 2). The comparison to ICESat results in a mean difference of $0.19 \mathrm{~m}$ with a standard deviation of $0.24 \mathrm{~m}$ (Figure 3). Even for a DEM generated with only one coverage these results prove full compliance with the absolute height requirements (Table 1). Also, the difference to SRTM shows very good results with a mean below $2 \mathrm{~m}$. As TanDEM-X is more accurate, remaining SRTM errors (e.g. typical SRTM waves) are visible in the difference image (Figure 4). The relative height accuracy, estimated by calculating the absolute differences between neighboring acquisitions, is well below the required $2 \mathrm{~m}$ (Figure 5).

\begin{tabular}{|l|c|c|c|c|}
\hline Reference & $\begin{array}{c}\text { Mean } \\
{[\mathrm{m}]}\end{array}$ & $\begin{array}{c}\text { Std.dev } \\
{[\mathrm{m}]}\end{array}$ & $\begin{array}{c}\text { LE90 } \\
{[\mathrm{m}]}\end{array}$ & \# points \\
\hline GPS & $\mathbf{- 0 . 5 6}$ & 1.14 & 1.75 & 4550 \\
\hline ICESat & $\mathbf{0 . 1 9}$ & 0.24 & 0.38 & 2021 \\
\hline SRTM & $\mathbf{1 . 8 0}$ & 1.49 & 2.30 & all \\
\hline Neighbor & $\mathbf{0 . 6 8}$ & 0.67 & 0.57 & all \\
\hline
\end{tabular}

Table 1: Differences of IDEM tile N49W98 to reference data (mean, standard deviation, linear 90\% point-to-point error, number of points)

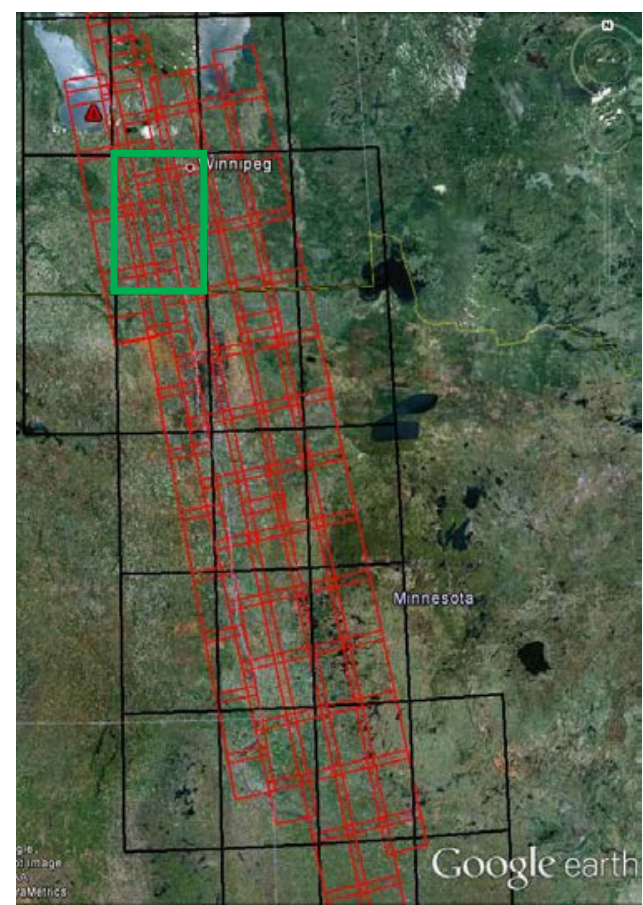

Figure 1: Overview test site Manitoba, RawDEMs marked red, $1^{\circ} \mathrm{x} 1^{\circ}$ tiles marked black, tile N49W98 marked green

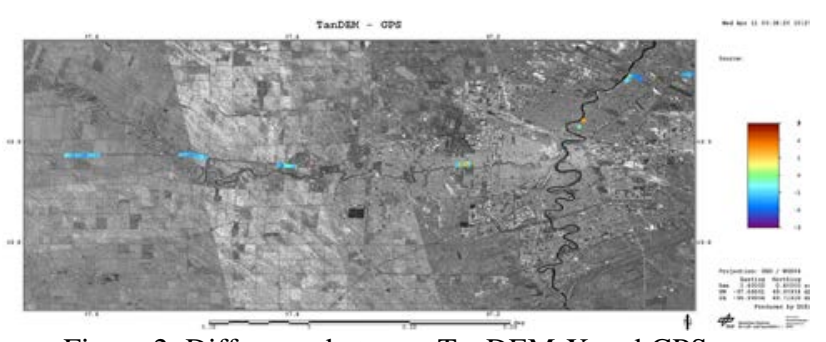

Figure 2: Difference between TanDEM-X and GPS on amplitude mosaick, North-Eastern part of tile N49W98 - area around Winnipeg, range of values [-3; 3]

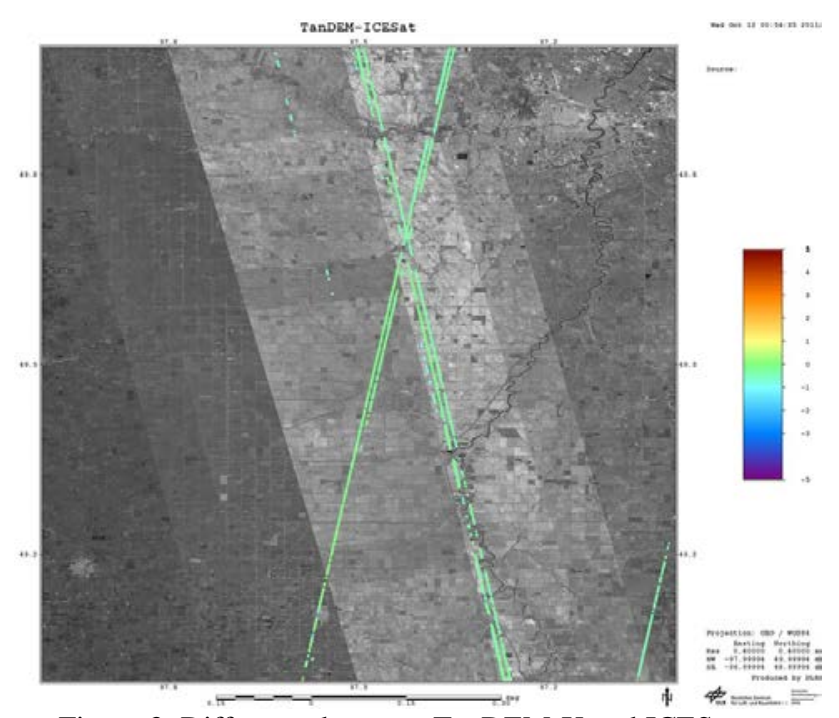

Figure 3: Difference between TanDEM-X and ICESat on amplitude mosaick, tile N49W98, range of values [-5; 5] 


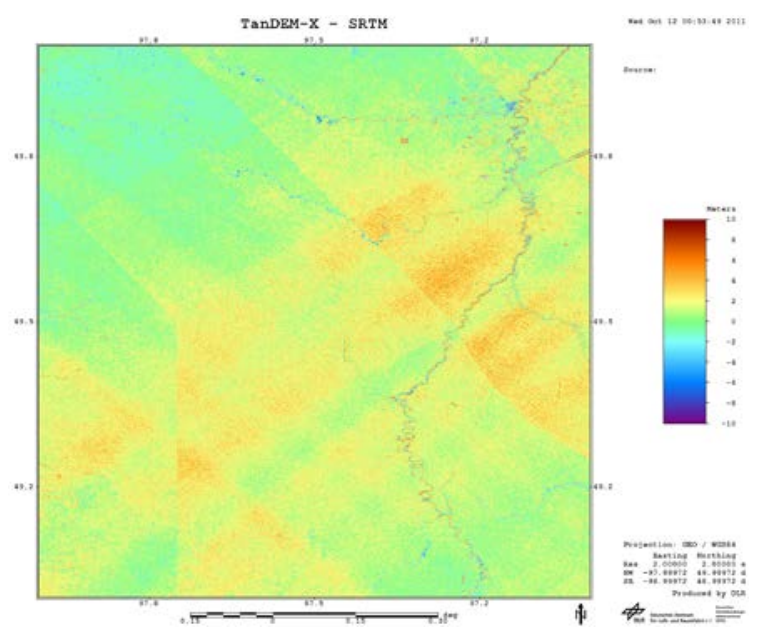

Figure 4: Difference between TanDEM-X and SRTM-C tile N49W98, range of values [-10; 10]

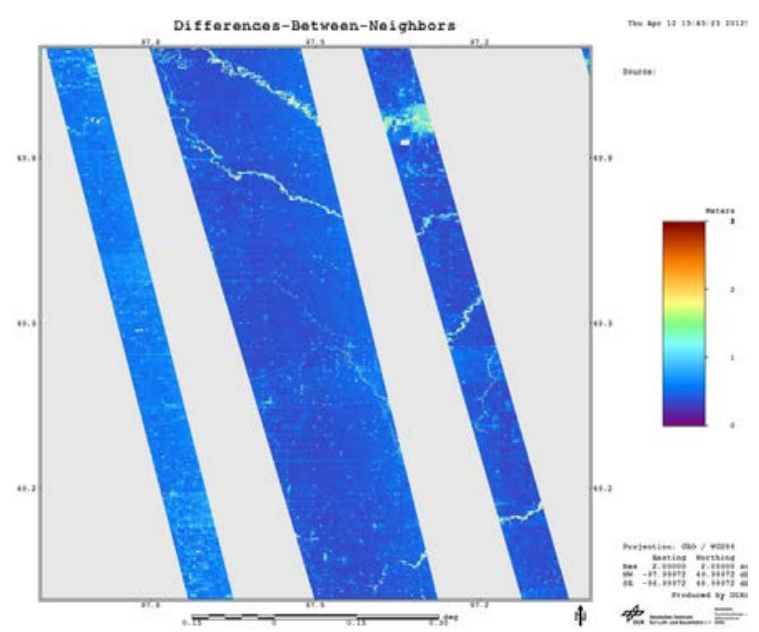

Figure 5: Difference between neighboring acquisitions, tile N49W98, range of values $[0 ; 3]$

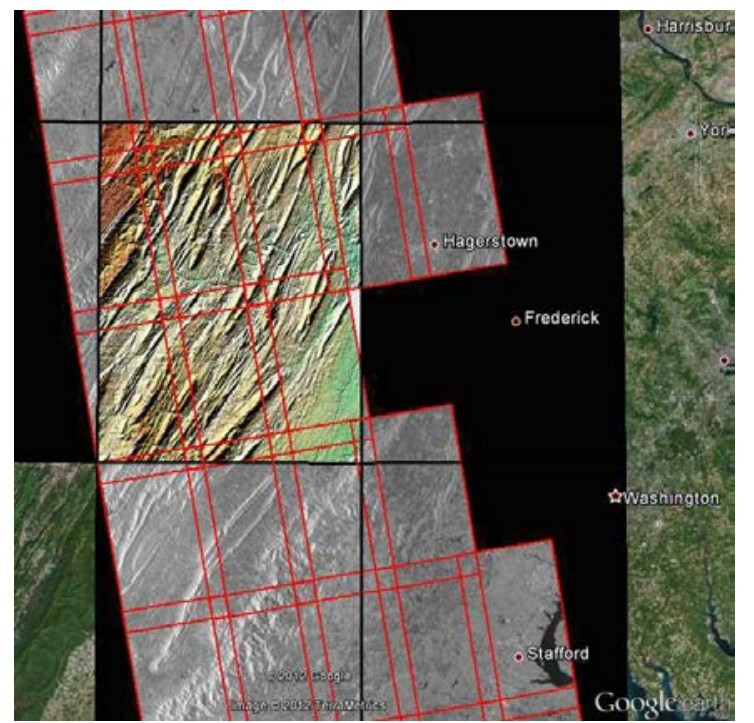

Figure 6: Overview test site Virginia. Color shaded DEM of tile N39W79 superimposed on amplitude mosaick, RawDEMs marked red
3.2.2 Test Site Virginia, USA: The second test site consists of 7 acquisitions covering an area from North Carolina up to Lake Ontario. Figure 6 shows the amplitude mosaick superimposed by the color shaded DEM of tile N39W79 and the RawDEM outlines (red). Note that RawDEMs with insufficient quality, e.g. because of large phase unwrapping errors, have to be reprocessed and were not used for IDEM generation.

The selected DEM tile N39W79 is located in the Appalachian Mountains and thus hilly and forested. The coherence in the SAR image is generally lower over forested areas. This causes noisy DEM values and has also an impact on the quality of calibration points. The calculated offsets and tilts are below $4 \mathrm{~m}$ and $3 \mathrm{~cm} / \mathrm{km}$ respectively.

A high resolution USGS Seamless DEM is available for this area. The USGS Seamless data is a terrain model and therefore has to be compared with caution to the TanDEM-X DEM, which is actually a surface model. This explains the "high" mean offset of almost $10 \mathrm{~m}$ (Table 2). However, in areas with less vegetation (green areas in Figure 7) the difference is in the range of about $2 \mathrm{~m}$. The comparison to ICESat results in a mean difference of $-3.67 \mathrm{~m}$ with a standard deviation of $6.68 \mathrm{~m}$ (Figure 8). The difference to SRTM shows a mean offset of $6.33 \mathrm{~m}$ and a standard deviation of 4.51m (Figure 9).

The relative height accuracy, estimated by calculating the absolute differences between neighboring acquisitions, is well below 3m (Figure 10).

\begin{tabular}{|l|c|c|c|c|}
\hline Reference & $\begin{array}{c}\text { Mean } \\
{[\mathrm{m}]}\end{array}$ & $\begin{array}{c}\text { Std.dev } \\
{[\mathrm{m}]}\end{array}$ & $\begin{array}{c}\text { LE90 } \\
{[\mathrm{m}]}\end{array}$ & \# points \\
\hline USGS & $\mathbf{9 . 9 4}$ & 8.20 & 12.39 & all \\
\hline ICESat & $\mathbf{- 3 . 6 7}$ & 6.68 & 10.94 & 1140 \\
\hline SRTM & $\mathbf{6 . 3 3}$ & 4.51 & 6.85 & all \\
\hline Neighbor & $\mathbf{2 . 6 7}$ & 2.72 & 3.00 & all \\
\hline
\end{tabular}

Table 2: Differences of IDEM tile N39W79 to reference data (mean, standard deviation, linear 90\% point-to-point error, number of points)

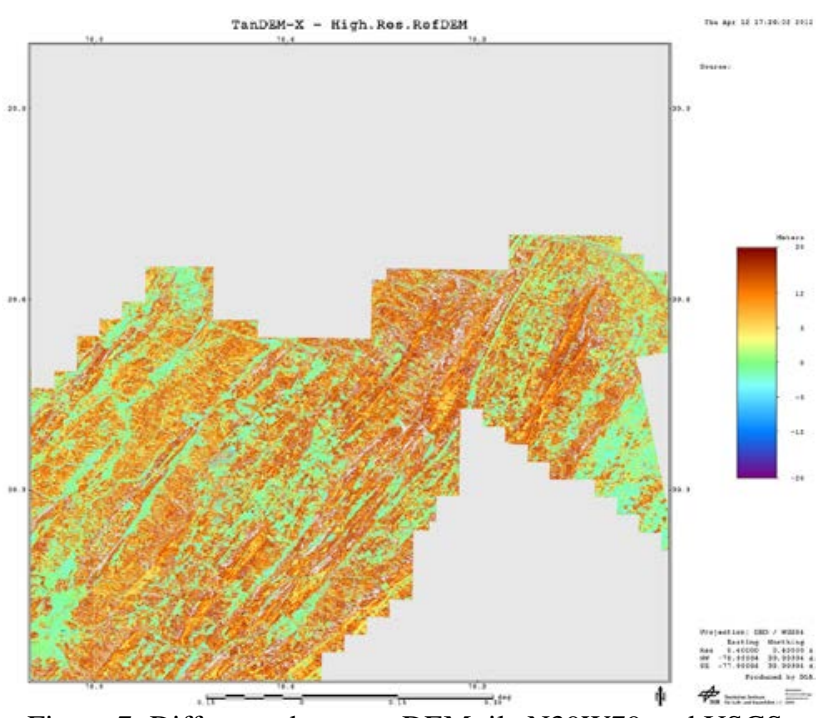

Figure 7: Difference between DEM tile N39W79 and USGS Seamless reference DEM (range of values $[-20 ; 20]$ ) 


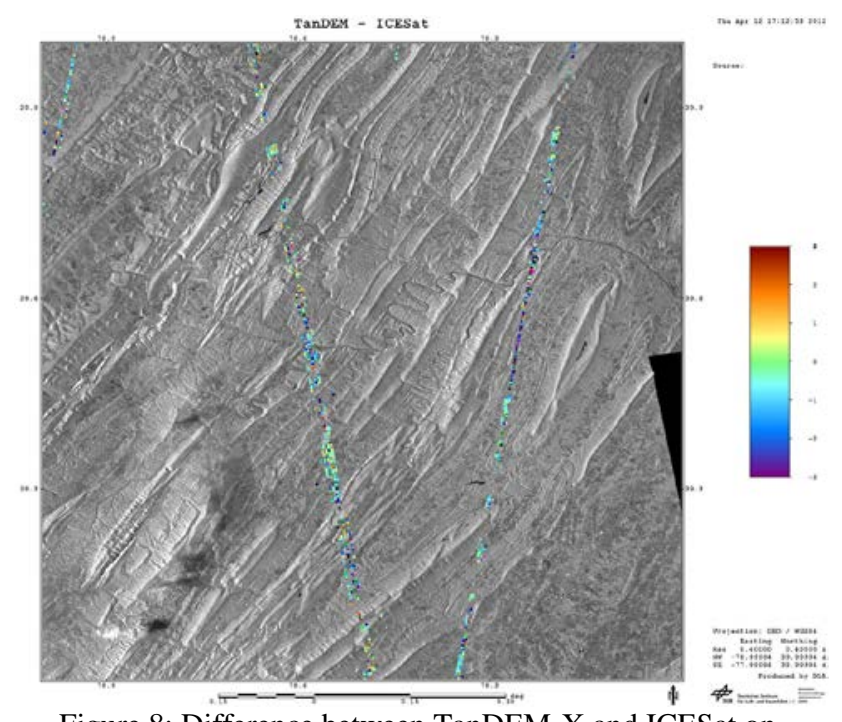

Figure 8: Difference between TanDEM-X and ICESat on amplitude mosaick, tile N39W79, range of values [-3; 3]

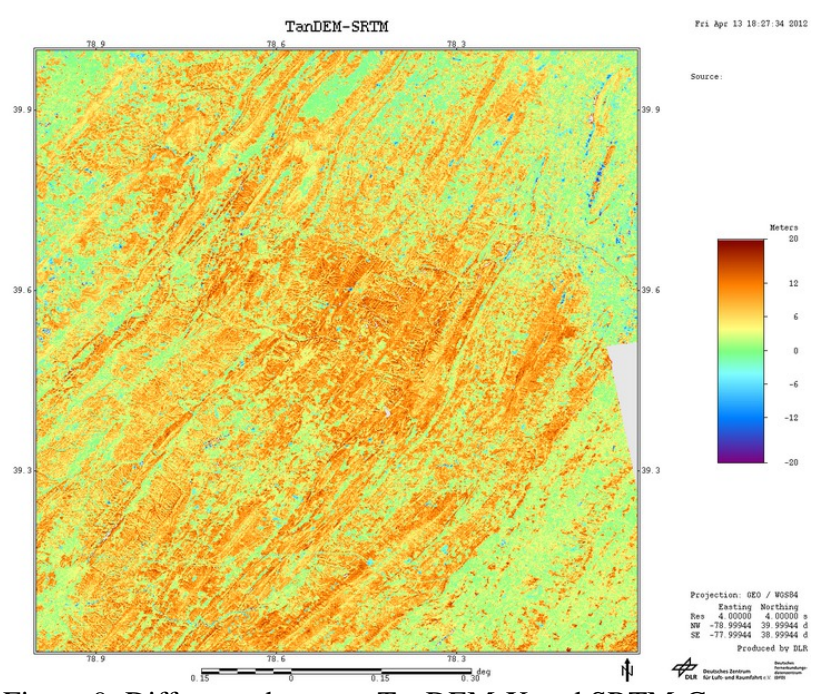

Figure 9: Difference between TanDEM-X and SRTM-C, tile N39W79, range of values [-20; 20]

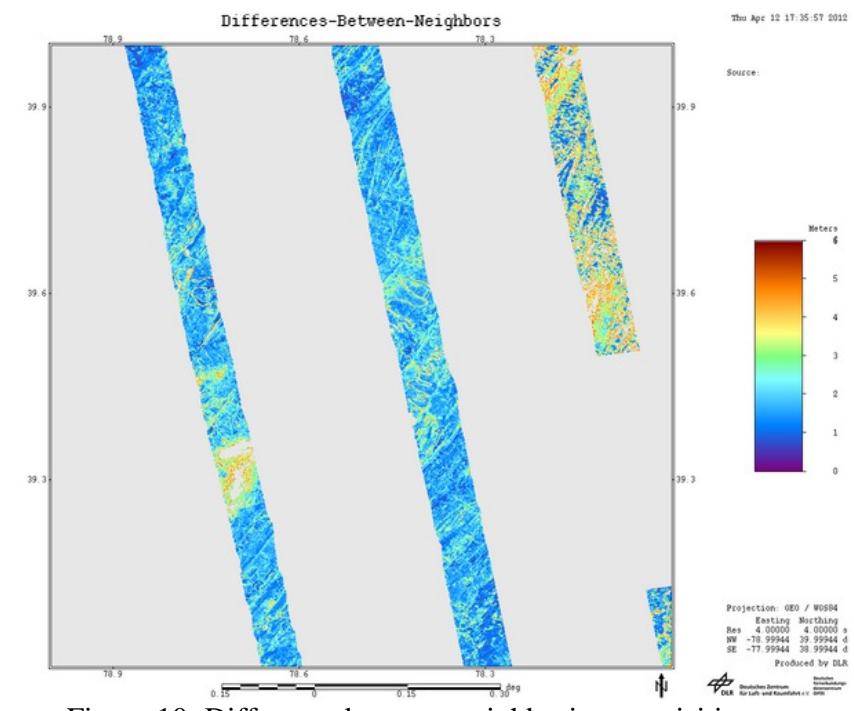

Figure 10: Difference between neighboring acquisitions, tile N39W79, range of values $[0 ; 6]$

\section{ADDITIONAL PRODUCT LAYERS}

Along with the digital elevation model, which is the main product of the TanDEM-X mission, additional information layers will be available. These additional layers are congruent with the DEM and have the same nominal spacing of 0.4 arcseconds. As mentioned above, the products are delivered in $1^{\circ} \times 1^{\circ}$ tiles and comprise the following layers:

\section{Height Error Map - HEM:}

The values represent the random height error for each DEM pixel in form of the standard deviation. The value is derived from the interferometric coherence and geometrical consideration and thus represents the result of rigorous error propagation.

\section{Layover and Shadow Mask - LSM:}

The values represent flags where layover and shadow areas are identified. The shadow information is based on (SRTM-C and GLOBE) and will therefore only be a rough estimate for many regions. The layover is based on the TanDEM-X DEM.

\section{Void Mask - VOM:}

The values represent flags where larger height inconsistencies, like differences above a predefined threshold (e.g. 10m) between different DEM acquisitions occur. These pixels should be masked out in the elevation model in order to obtain a more reliable DEM.

\section{Water Indication Mask - WAM:}

The values represent flags where water bodies are identified during processing. Water is identified by three different extraction methods:

- with a strong amplitude threshold, normally $<40$ digital number (DN)

- with a more relaxed amplitude threshold, normally $<60$ DN

- with a coherence threshold, normally $<0.23$

The number of occurrences reflects the number of single acquisitions fulfilling the respective threshold. The maximum number of annotated occurrences for each method is three.

\section{Interpolation Mask - IPM:}

The values indicate pixel where small spikes and wells were interpolated.

\section{Coverage Mask - COV:}

The values indicate the number of acquisitions contributing a valid DEM pixel to the elevation model.

\section{Amplitude Mosaick - AMP:}

The values represent the mosaic of the geocoded SAR amplitude images corresponding to the active channel of the DEM acquisitions.

Detailed information about the TanDEM-X product (DEM and additional layers) can be found in the "TanDEM-X DEM Product Specification” (TanDEM-X Ground Segment 2011).

In the following a subset of approximately $8 \mathrm{~km} \mathrm{x} 8 \mathrm{~km}$ was extracted in full $0.4 \times 0.4$ arcsecond resolution $30 \mathrm{~km}$ east of Jacksonville, North Carolina from the tile N34W78 (center of subset $\sim 34^{\circ} 46^{\prime} \mathrm{N}, 7^{\circ} 9^{\prime} \mathrm{W}$ ). The result of the WAM extraction is exemplarily depicted for tis subset. The amplitude image shows a river expanding towards its water mouth into the Atlantic (Figure 11). The corresponding height values in the DEM appear noisy as interferometric data sets have generally low coherence over water (Figure 12). On the over hand details like the clear-cut for the railroad route running from east to west are clearly visible (slightly left of the center).

Figure 13 shows the Height Error Map where bright values indicate larger height error and lower coherence, respectively. 


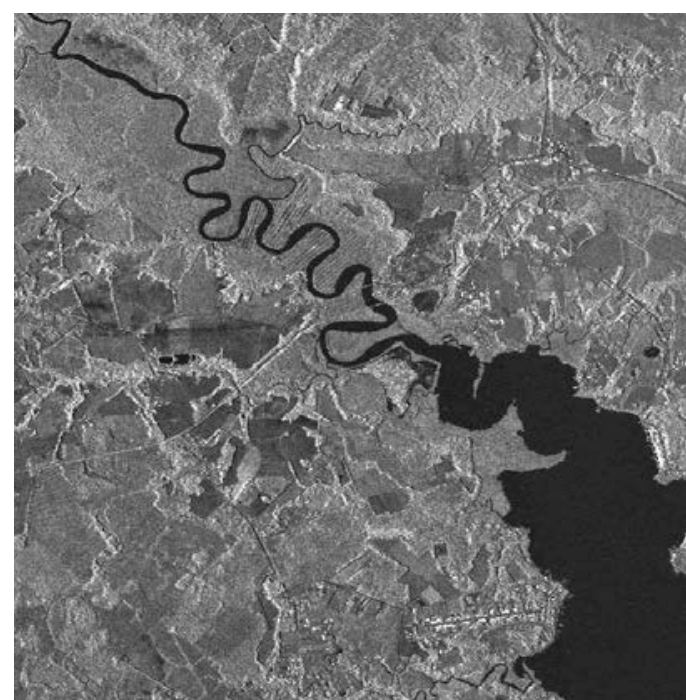

Figure 11: Subset tile N34W78, amplitude mosaick

For the water indication mask the amplitude and the coherence are evaluated as mentioned above. Figure 14 shows a visualisation of the WAM. The beige colored pixels indicate water derived solely from the amplitude, light blue indicates water found in the amplitude and the coherence. Dark blue indicates water found in the amplitude and the coherence of two overlapping acquisitions.

Near the scene center, where two bridges cross the river, it can be seen that the amplitude and coherence flag complement one another very well. Although, the coherence does not indicate water here it is found by the amplitude threshold.

Smaller lakes, like e.g. the two which can be seen in the middle left of the amplitude image, fall below the minimum mapping unit for lakes and rivers which is two hectares $\left(20,000 \mathrm{~m}^{2}\right)$.

In a later editing step it is planned to use the water indication mask for flattening noisy DEM areas over water. A first study for this DEM editing step and more detailed information about WAM generation can be found in (Wendleder et al. 2012).

\section{CONCLUSIONS}

First calibrated and mosaicked intermediate TanDEM-X DEMs were presented. In flat and sparsely vegetated areas the validation shows an absolute height accuracy of better than $2 \mathrm{~m}$ with respect to all reference data.

Also in hilly and vegetated areas the height criteria can be met already with the first coverage. The difference to USGS Seamless data with about $10 \mathrm{~m}$ is explainable as this dataset is a terrain model, while the TanDEM-X DEM is a surface model. On the other hand the comparison to SRTM and ICESat show good absolute accuracy of better than $7 \mathrm{~m}$.

More mountainous test sites were not considered up to now, as there may be phase unwrapping errors. These errors need at least an additional acquisition and dual baseline processing to be resolved for DEM generation.

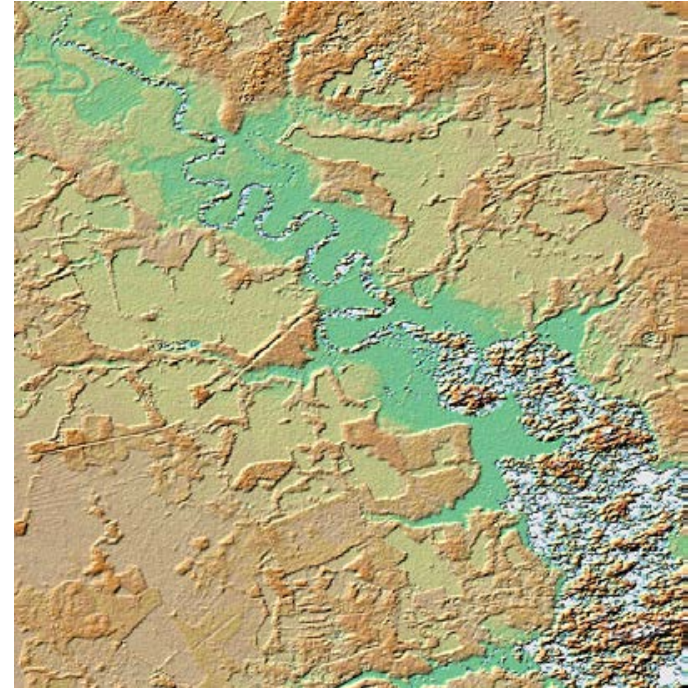

Figure 12: Subset tile N34W78, color shaded DEM

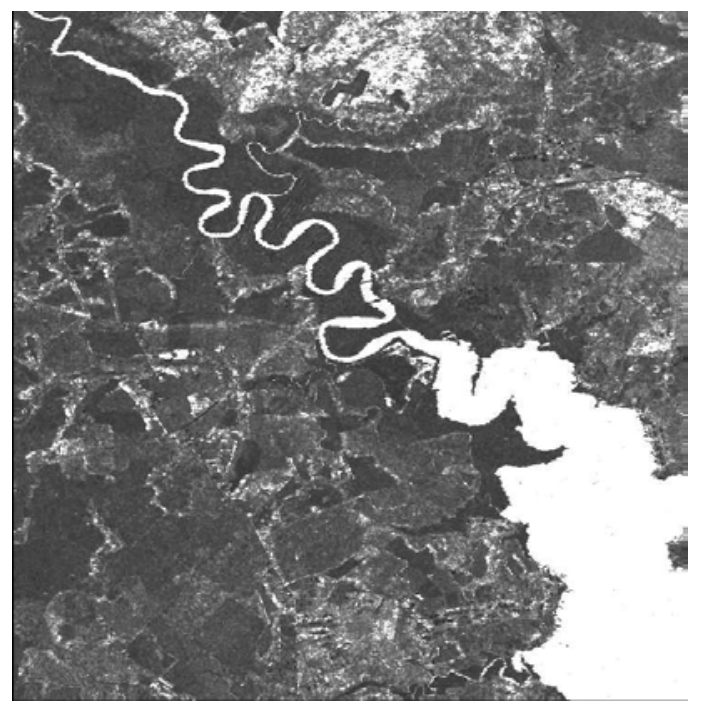

Figure 13: Subset tile N34W78, height error map

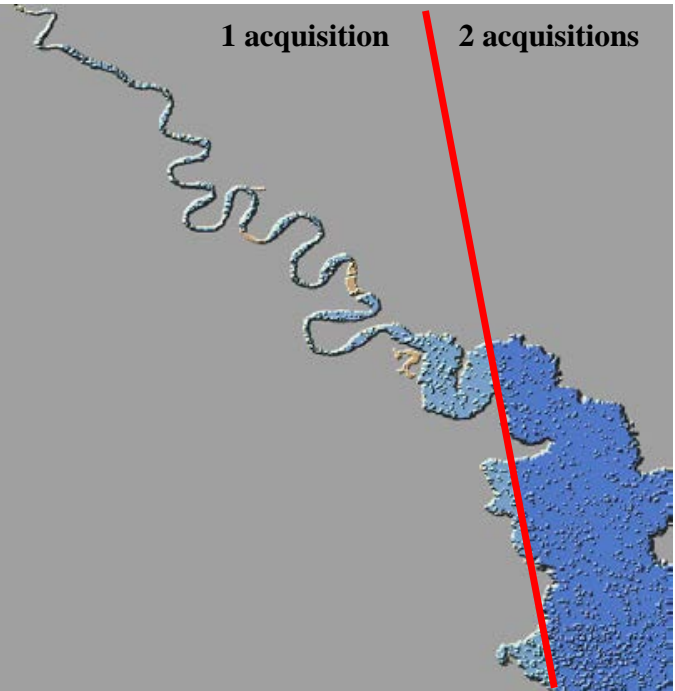

Figure 14: Subset tile N34W78, water indication mask, beige: water derived from amplitude, light blue: water derived from amplitude and coherence, dark blue: water derived from amplitude and coherence in two acquisitions 


\section{REFERENCES}

Fritz, T., Breit, H., Adam, N., Eineder, M., Lachaise, M., 2008. Interferometric SAR Processing: From TerraSAR-X to TanDEM-X. Proceedings of EUSAR 2008, Friedrichshafen, Germany, Vol. 4, pp. 39 - 42.

Gruber, A., Wessel, B., Huber, M., 2009. TanDEM-X DEM calibration: Correction of systematic DEM errors by block adjustment. Proceedings of IGARSS 2009, Cape Town, South Africa.

Huber, M., Wessel, B., Kosmann, D., Felbier, A., Schwieger, V., Habermeyer, M., Wendleder, A., Roth, A., 2009. Ensuring globally the TanDEM-X height accuracy: Analysis of the reference data sets ICESat, SRTM, and KGPS-Tracks. Proceedings of IGARSS 2009, Cape Town, South Africa.

Huber, M., Gruber, A., Wessel, B., Breunig, M., Wendleder, A., 2010. Validation of tie-point concepts by the DEM adjustment approach of TanDEM-X. Proceedings of IGARSS 2010, Honolulu, Hawaii, USA.

Hueso Gonzales, J., Krieger, G., Walter Antony, J., Bachmann, M., Schrank, D., Schwerdt, M., De Zan, F. Rodriguez-Cassola, M., 2011. Baseline and Bistatic System Calibration in the TanDEM-X Mission. IGARSS 2011, 2011-07-24 - 2011-07-29, Vancouver, Kanada.

Krieger, G., Moreira, A., Fiedler, H., Hajnsek, I., Werner, M., Younis, M., Zink, M., 2007. TanDEM-X: A Satellite Formation for High Resolution SAR Interferometry. IEEE Transactions on Geoscience and Remote Sensing, 45(11), pp. 3317-3341.

TanDEM-X Ground Segment, 2011. “TanDEM-X DEM Product Specification”, TD-GS-PS-0021, http://tandemxscience.dlr.de/pdfs/TD-GS-PS-0021_DEM-Product-

Specification_v1.7.pdf (12 Apr. 2011).

Wendleder, A., Wessel, B., Roth, A., Breunig, M., Martin, K., Wagenbrenner, S., "TanDEM-X Water Indication Mask: Generation and First Evaluation Results“, IEEE Journal of Selected Topics in Applied Earth Observations and Remote Sensing" (JSTARS), 2012, in print

Wessel, B., Gruber, A., Huber, M., Roth, A., 2009. TanDEM$\mathrm{X}$ : Block adjustment of interferometric height models. Proceedings of ISPRS Hannover Workshop 2009 "HighResolution Earth Imaging for Geospatial Information”, June 2 5, 2009, Hannover, Germany 